Ariane Dierke*, Finja Borowski, Swen Großmann, Christoph Brandt-Wunderlich, Claudia Matschegewski, Paula Rosam, Nico Pilz, Paul Reister, Rebekka Einenkel, Ulf Hinze, Jonas Keiler, Michael Stiehm, Kerstin Schümann, Andrea Bock, Boris Chichkov, Niels Grabow, Andreas Wree, Marek Zygmunt, Klaus-Peter Schmitz and Stefan Siewert

\title{
Development of a biodegradable microstent for minimally invasive treatment of Fallopian tube occlusions
}

\begin{abstract}
Obstructions of the Fallopian tube represent one of the most common reasons for an unfulfilled desire to have children. Microstent technology opens up new therapeutic possibilities to restore the natural lumen of the Fallopian tube within a single treatment. Within the current work we developed a self-expandable biodegradable microstent for gynecological applications. Based on a novel microstent design, prototypes were manufactured from poly-L-lactide tubing by means of fs-laser cutting. Microstent prototypes were characterized morphologically by means of scanning electron microscopy and biaxial laser scanning. As manufactured, a microstents outside diameter of about $2.3 \mathrm{~mm}$ and a strut thickness / width of about $114 \mu \mathrm{m} /$ $103 \mu \mathrm{m}$ was measured. Mechanical characterization of microstents included bending as well as crimping and release behavior. After crimping to a minimum diameter of $0.8 \mathrm{~mm}$ and consecutive release, a microstent recovery to a diameter of $1.8 \mathrm{~mm}$ was found. Therefore, proof-of-concept for the self-expandable microstent could be successfully provided.
\end{abstract}

\footnotetext{
${ }^{*}$ Corresponding author: Ariane Dierke: Institute for ImplantTechnology and Biomaterials e.V., FriedrichBarnewitz-Str. 4, 18119 Rostock-Warnemünde, Germany, e-mail: ariane.dierke@uni-rostock.de

Finja Borowski, Swen Großmann, Christoph BrandtWunderlich, Claudia Matschegewski, Paula Rosam, Michael Stiehm, Andrea Bock, Klaus-Peter Schmitz, Stefan Siewert: Institute for ImplantTechnology and Biomaterials e.V., 18119 Rostock-Warnemünde, Germany Nico Pilz, Paul Reister, Kerstin Schümann, Niels Grabow, Klaus-Peter Schmitz: Institute for Biomedical Engineering, Rostock University Medical Center, 18119 RostockWarnemünde, Germany

Rebekka Einenkel, Marek Zygmunt: Department of Obstetrics and Gynecology, University Medicine Greifswald, 17475 Greifswald, Germany

Ulf Hinze, Boris Chichkov: Institute of Quantum Optics, Leibniz University Hannover, 30167 Hannover, Germany Jonas Keiler, Andreas Wree: Department of Anatomy, Rostock University Medical Center, 18057 Rostock, Germany
}

Keywords: Biodegradable microstent, Fallopian tube occlusion, enabling pregnancy, fertility treatment.

https://doi.org/10.1515/cdbme-2020-3019

\section{Introduction}

In about $35 \%$ of cases, female sterility arises from obstructions of the Fallopian tube, particularly proximal tube occlusions (PTO) [1]. The Fallopian tube as a hormone-dependent valve is responsible for transport of the ovum. Therefore, an intact mobility of the fimbrial funnel as well as complete patency is crucial. The proximal end of the Fallopian tube is formed by longitudinal folds of the mucous membrane with a small lumen. Tubal disorders are commonly related to congenital anomalies, acute or chronic inflammatory diseases, endometriosis and other pathologies resulting in partial or total PTO [2]. We developed a therapy concept based on a biodegradable self-expandable microstent (Fig. 1).

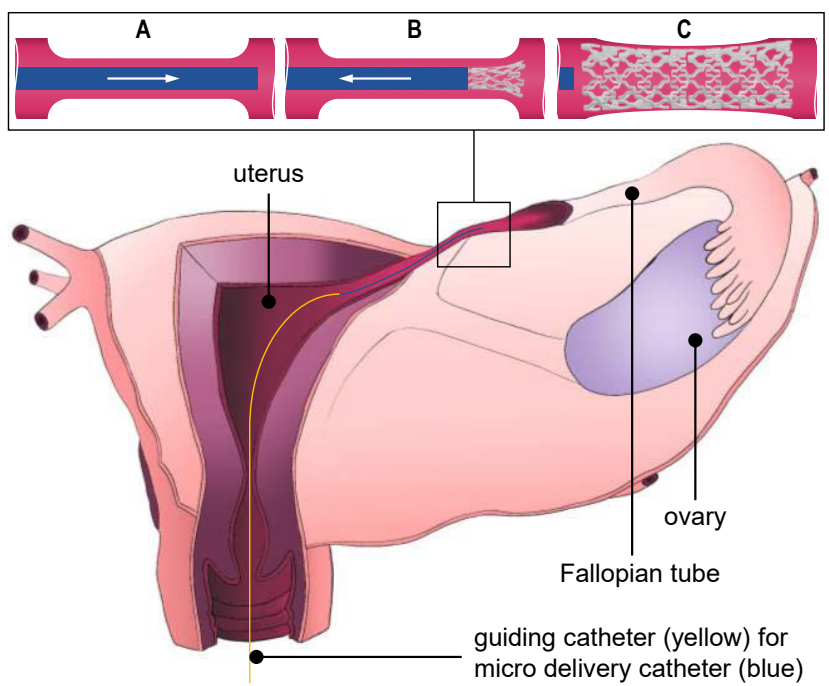


Current treatment options include in vitro fertilisation (IVF) or minimally invasive transcervical catheterisation of the Fallopian tube as an alternative to the more risky surgery. Success rates of conventional treatment options range between only $20 \%$ to $50 \%$ for a subsequent pregnancy [3].

Therefore, our biodegradable self-expandable microstent for minimally invasive treatment of Fallopian tube occlusions represents a promising treatment option. The implant device should restore the patency of the Fallopian tube by overcoming the external stenosis (e.g. due to fibrosis) and restore the tubal valve function. Within the current study, feasibility of the microstent concept was analyzed.

\section{Materials and methods}

\subsection{Microstent design}

General requirements of the microstent include biocompatibility and degradation within a time frame of approximately two years. For a minimized influence of the device on the Fallopian tube epithelium, the stent structure should be designed as flexible as possible with a low surface coverage of less than $15 \%$. Microstent design was developed using 3DCAD (computer-aided design) software Creo Parametric 5.0 (PTC Inc., USA), considering anatomical boundary conditions as well as manufacturing-relevant aspects (Tab. 1).

Table 1: Geometrical parameters of self-expanding microstent.

\begin{tabular}{cccc}
\hline $\begin{array}{c}\text { Stent } \\
\text { length }\end{array}$ & $\begin{array}{c}\text { Inside diameter } / \\
\text { outside diameter } \\
\boldsymbol{d}_{\boldsymbol{i}} / \boldsymbol{d}_{\boldsymbol{o}}\end{array}$ & $\begin{array}{c}\text { Wall } \\
\text { thickness } \\
\boldsymbol{t}\end{array}$ & $\begin{array}{c}\text { Strut } \\
\text { width } \\
\boldsymbol{w}_{\boldsymbol{s}}\end{array}$ \\
\hline $20.0 \mathrm{~mm}$ & $2.0 \mathrm{~mm} / 2.2 \mathrm{~mm}$ & $100 \mu \mathrm{m}$ & $100 \mu \mathrm{m}$ \\
\hline
\end{tabular}

Figure 2 shows the open-cell design of the microstent. The device is composed of 12 meander ring segments, each $l_{s}=1.7 \mathrm{~mm}$ and $u=6.6 \mathrm{~mm}$ wide in longitudinal and circumferential direction. Eight meanders are arranged over the circumference, per ring segment respectively. Longitudinally, the meander ring segments were joint by four connector elements, respectively.

The microstent design (Fig. 2 B) represents the expanded state and offers extensive reserves for diameter reduction. To avoid plastic deformations during the crimping process, the design was optimized with regard to minimized strain amplitudes. The corresponding finite-element analyses were not described within the current work. In the expanded state, minor surface coverage of $13 \%$ was achieved.
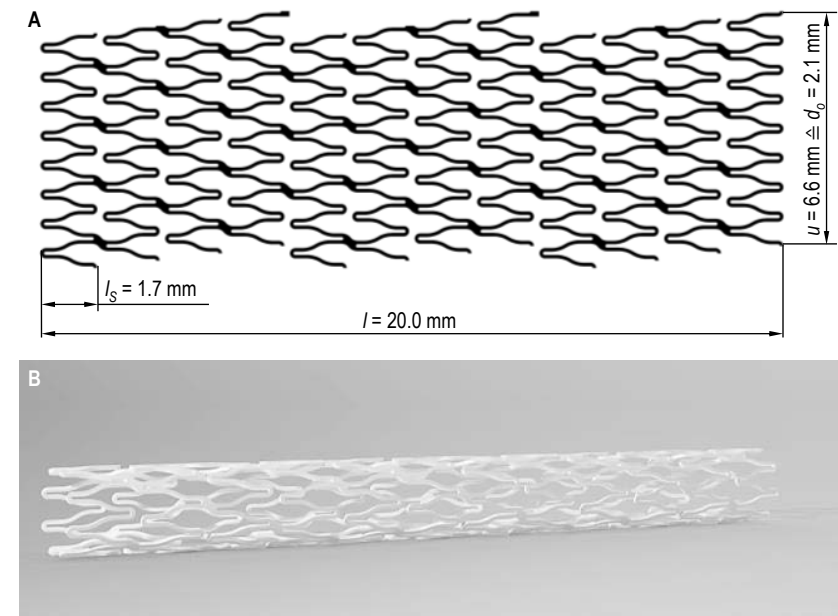

Figure 2: Two-dimensional representation of the microstent design $(A)$ and the corresponding 3D-CAD model in the expanded state, which represents the microstent configuration as manufactured $(B)$.

\subsection{Manufacturing of microstent- prototypes}

Poly(L-lactide) (PLLA, Resomer L210, Evonik Health Care GmbH, Germany) was used as base material. PLLA represents an absorbable thermoplastic polymer which is widely used in biomedical applications and offers favourable mechanical properties in the field of stent technology, such as a high elastic modulus of $1,200 \mathrm{MPa} \leq E \leq 2,700 \mathrm{MPa}$, a tensile strength of $28 \mathrm{MPa} \leq \sigma_{m} \leq 50 \mathrm{MPa}$ and an elongation at break of $\varepsilon_{B}=6 \%$. Absorption rates of 1.5 to 5 years are described in the literature [4].

For the manufacturing of tubular semifinished products, a solution of $4 \mathrm{~g}$ PLLA in $400 \mathrm{ml}$ chloroform (Carl Roth $\mathrm{GmbH}+\mathrm{Co}$. KG, Germany) was prepared. The dipping process is carried out using a self-developed dipping robot. During repeated immersion in the solution, the dipping mandrels $\left(d_{m}=2.0 \mathrm{~mm}\right)$ are rotated by $180^{\circ}$ per dipping repetition, thus achieving a homogeneous distribution of tubing wall thickness. Measurement of the tubing outside diameter was conducted by means of a biaxial laser system (ODAC 32 XY, ZUMBACH Electronic AG, Switzerland).

Manufacturing of microstent prototypes was conducted using a $780 \mathrm{~nm}$ fs-laser (Spectra-Physics, Santa Clara, USA) in combination with a positioning system (Aerotech Laserturn 5, Aerotech, Inc., USA). A laser pulse of $50 \mathrm{fs}$ and a repetition rate of $1 \mathrm{kHz}$ with a pulse energy of up to $3.5 \mathrm{~mJ}$ was used.

Scanning electron microscopy (SEM, Quattro S, Thermo Fisher Scientific Inc., USA) was used to evaluate surface and edge quality of the microstent prototypes. Imaging was conducted in low vacuum mode without sample 
preparation by means of conductive layers at a pressure of $50 \mathrm{~Pa}$ and an acceleration voltage of $5 \mathrm{kV}$.

Microstent outside diameter was measured optically by means of the biaxial laser system in increments of $0.02 \mathrm{~mm}$ along the longitudinal axis.

\subsection{In vitro testing of microstent prototypes}

For mechanical characterization of microstent prototypes, bending stiffness and radial force were investigated at $37^{\circ} \mathrm{C}$. For determination of the bending stiffness $E I$, the microstent prototypes were clamped on the one side and the free end was deflected laterally for $u=300 \mu \mathrm{m}$. A clamping length of $l_{c}=9 \mathrm{~mm}$ was used. Bending reaction force $F_{b}$ on five circumferential positions was measured using an integrated load cell (PW4MC3/300G-1, Hottinger Baldwin Messtechnik, Germany). For each circumferential position three force values were recorded and averaged. Bending stiffness was calculated according to formula 1 .

$$
E I=\frac{F_{b} \cdot l_{c}^{3}}{3 \cdot u}
$$

Radial force $F_{r}$ as a function of diameter $d$ was measured in accordance with DIN EN ISO 2539-2 using the Blockwise Radial Force Tester TTR 2 in combination with an iris diaphragm (J-Crimp Station RJU124, Blockwise Engineering LLC, USA). Crimping was conducted subsequently in increments of $0.1 \mathrm{~mm}$ to minimum crimping diameters ranging from $d_{c}=2.2 \mathrm{~mm}$ to $0.8 \mathrm{~mm}$.

\section{Results}

\subsection{Manufacturing of microstent prototypes}

Tubular semifinished products with reproducible wall thickness of $t=(97.2 \pm 6.0) \mu \mathrm{m}(n=8)$ were manufactured. Further processing resulted in two microstent prototypes. As manufactured, a microstent outside diameter of $d_{o}=(2.35 \pm 0.08) \mathrm{mm}$ and $d_{o}=(2.28 \pm 0.06) \mathrm{mm}$ with a minor variation along the longitudinal axis was measured for prototype \#1 and \#2, respectively. Strut width and wall thickness of approximately $w_{s}=114 \mu \mathrm{m}$ and $t=103 \mu \mathrm{m}$ were determined at different measuring points using SEM. An exemplary macro and a SEM image of microstent prototype \#2 are shown in Fig. 3.

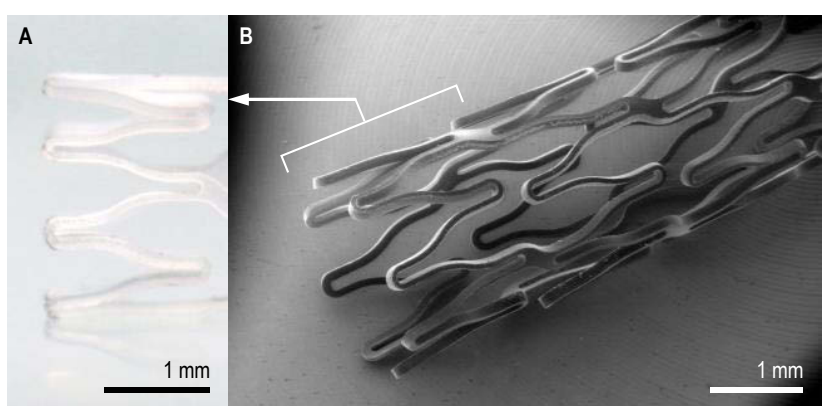

Figure 3: Exemplary macro $(A)$ and SEM image (B) of microstent prototype \#2.

\subsection{In vitro testing of microstent prototypes}

The maximum bending reaction force $F_{b}$ at maximum lateral deflection of $u=300 \mu \mathrm{m}$ and the bending stiffness $E I$ as results of the bending tests are summarized in Tab. 2 .

Table 2: Results of bending tests with two microstent prototypes: maximum bending reaction force $F_{b}$ at maximum lateral deflection of $u=300 \mu \mathrm{m}$ and bending stiffness $E l$ based on five circumferential measurement positions $(n=3)$, respectively.

\begin{tabular}{lll}
\hline microstent prototype & $\boldsymbol{F}_{\boldsymbol{b}}[\mathrm{N}]$ & $\boldsymbol{E l}\left[\mathrm{Nmm}^{2}\right]$ \\
\hline$\# 1$ & $5.40 \pm 0.57$ & $1.09 \pm 0.19$ \\
$\# 2$ & $5.30 \pm 0.63$ & $1.07 \pm 0.25$ \\
\hline
\end{tabular}

Radial force measurements were conducted using prototype $\# 1$. Figure 4 depicts the relation of radial force $F_{r}$ and diameter $d$, exemplary for minimum crimping diameters of $d_{c}=2.0 \mathrm{~mm}, 1.5 \mathrm{~mm}$ and $1.0 \mathrm{~mm}$.

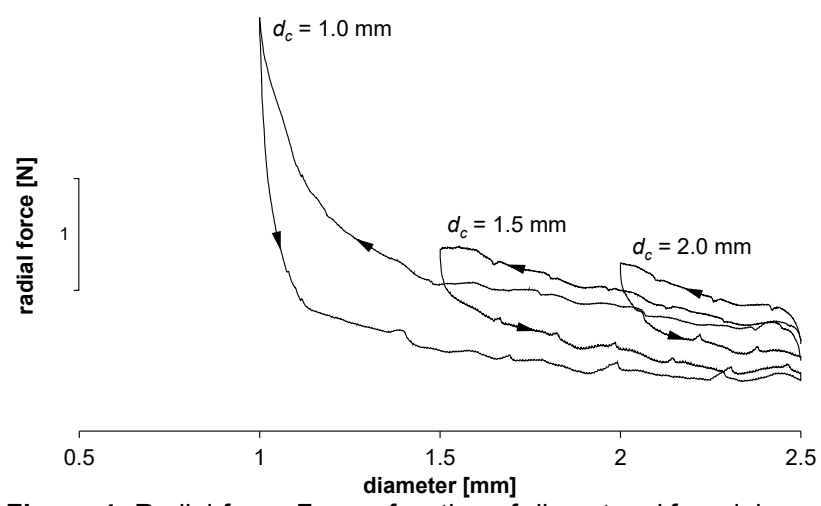

Figure 4: Radial force $F_{r}$ as a function of diameter $d$ for minimum crimping diameters $d_{c}=2.0 \mathrm{~mm}, 1.5 \mathrm{~mm}$ and $1.0 \mathrm{~mm}$; Characterization of microstent prototype \#1. 
The maximum radial force increases from $F_{r}=0.32 \mathrm{~N}$ to $37.14 \mathrm{~N}$ with degreasing crimping diameter from $d_{c}=2.2 \mathrm{~mm}$ to $0.8 \mathrm{~mm}$ (Fig. 5).

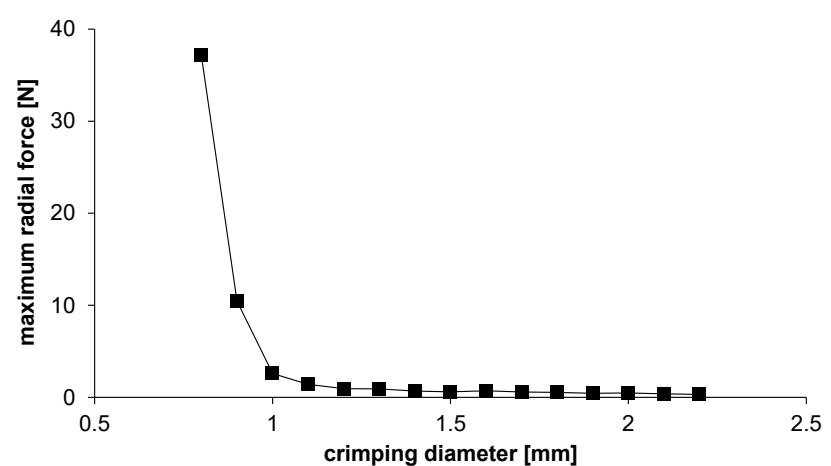

Figure 5: Maximum radial force $F_{r}$ as a function of minimum crimping diameter $d_{c}$; Characterization of microstent prototype \#1.

Figure 6 illustrates the microstent diameter after crimping to various diameters and consecutive release. Due to plastic strain, the diameter after crimping and release decreases with decreasing crimping diameters. Nevertheless, after crimping to a diameter of $d_{c}=0.8 \mathrm{~mm}$ and consecutive release, the microstent still recovers to $1.8 \mathrm{~mm}$, corresponding to an acceptable diameter recovery of $77 \%$ compared with its diameter as manufactured.

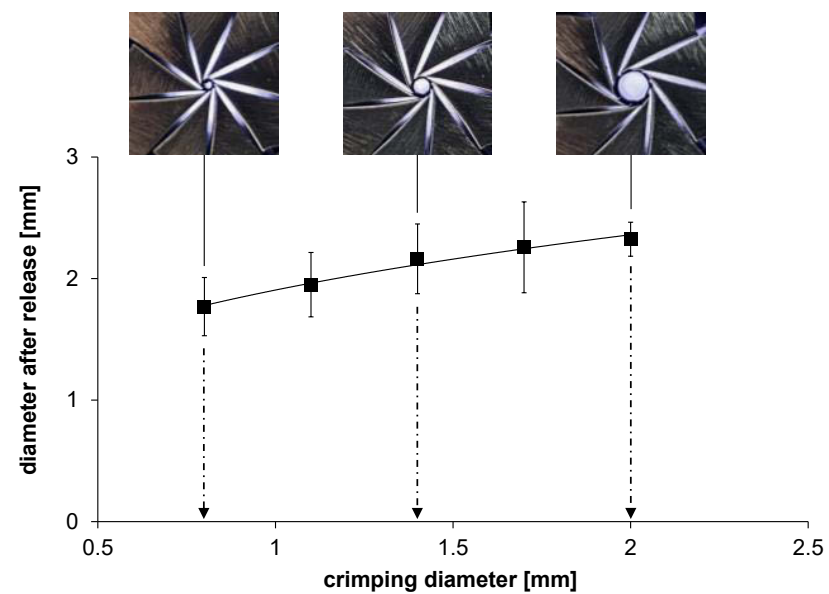

Figure 6: Diameter of microstent prototype \#1 after crimping to diameters from $d_{c}=2.0 \mathrm{~mm}$ to $0.8 \mathrm{~mm}$ and consecutive release; diameter after crimping and release measured using biaxial laser device; mean value \pm standard deviation of microstent diameter along the longitudinal axis; extrapolation for a further reduction of crimping diameter.

\section{Discussion}

The current work represents an initial attempt to develop a self-expandable biodegradable microstent for minimally invasive treatment of Fallopian tube occlusions. The presented technologies are suitable for the manufacturing of microstent prototypes with reproducible quality.

The Microstent prototypes show low values for bending stiffness, comparable with commercially available biodegadable stents for vascular application such as BIOTRONIK Magmaris 3.0/20 $\left(E I=0.89 \mathrm{Nmm}^{2}\right)$, Abbott Absorb GT1 $3.0 / 18\left(E I=4.20 \mathrm{Nmm}^{2}\right)$ or Elixir DESolve $3.0 / 18\left(E I=1.50 \mathrm{Nmm}^{2}\right)$ [5]. Commercially available drugeluting stents for vascular application such as BIOTRONIK Orsiro 3.0/15 $\left(E I=8.8 \mathrm{Nmm}^{2}\right)$ are commonly by one order of magnitude stiffer [6].

The presented analyses of crimping and release behavior strongly indicate feasibility of a polymeric self-expandable microstent for gynecological applications in combination with a micro delivery catheter with an inner diameter of $0.8 \mathrm{~mm}$. Further investigations are planned with regard to simulated use in an in vitro and ex vivo model.

\section{Author Statement}

Research funding: Financial support by the Federal Ministry of Education and Research (BMBF) within RESPONSE "Partnership for Innovation in Implant Technology" is gratefully acknowledged. Conflict of interest: Authors state no conflict of interest.

\section{References}

[1] Diagnostic and therapy before assisted reproductive treatments. Guideline of the DGGG, OEGGG and SGGG (S2KLevel, AWMF Registry No. 015/085, 02/2019). www.awmf.org, assessed march 23, 2020

[2] Rohen JW, Lütjen-Drecoll E. Funktionelle Histologie. kurzgefaßtes Lehrbuch der Zytologie, Histologie und mikroskopischen Anatomie des Menschen nach funktionellen Gesichtspunkten. 4. Aufl. Stuttgart: F. K. Schattauer Verlagsgesellschaft $\mathrm{mbH} ; 2000$.

[3] Allahbadia GN, Merchant R. Fallopian Tube Recanalization: Lessons Learnt and Future Challenges. Women's Health 2010; Volume: 6; issue: 4; 531-549.

[4] Martin DP, Williams SF. Medical applications of poly-4hydroxybutyrate: a strong flexible absorbable biomaterial. Biochemical Engineering Journal. 2003;16(2)97-105.

[5] Schmidt W, Behrens P, Brandt-Wunderlich C, Siewert S, Grabow N, Schmitz KP. In vitro performance investigation of bioresorbable scaffolds - Standardtests for vascular stents and beyond. Cardiovascular Revascularization Medicine. 2016;17(6)375-383.

[6] Schmidt W, Lanzer P, Behrens P, Brandt-Wunderlich C, Öner A, Ince H, Schmitz KP, Grabow N. Direct comparison of coronary baremetal vs. drug-eluting stents: same platform, different mechanics? European Journal of Medical Research; 2018;23(1):2. 